\title{
Cellulose Fiber-Reinforced PLA versus PP
}

\author{
Nina Graupner and Jörg Müssig \\ The Biological Materials Group, Department of Biomimetics, HSB-City University of Applied Sciences, Neustadtswall 30, \\ 28199 Bremen, Germany
}

Correspondence should be addressed to Nina Graupner; nina.graupner@hs-bremen.de

Received 26 January 2017; Revised 7 May 2017; Accepted 24 May 2017; Published 4 July 2017

Academic Editor: Yulin Deng

Copyright (C) 2017 Nina Graupner and Jörg Müssig. This is an open access article distributed under the Creative Commons Attribution License, which permits unrestricted use, distribution, and reproduction in any medium, provided the original work is properly cited.

\begin{abstract}
The present study focuses on a comparison between different cellulose fiber-reinforced thermoplastics. Composites were produced with 30 mass-\% lyocell fibers and a PLA or PP matrix with either an injection (IM) or compression molding (CM) process. Significant reinforcement effects were achieved for tensile strength, Young's modulus, and Shore D hardness by using lyocell as reinforcing fiber. These values are significantly higher for PLA and its composites compared to PP and PP-based composites. Investigations of the fiber/matrix adhesion show a better bonding for lyocell in PLA compared to PP, resulting in a more effective load transfer from the matrix to the fiber. However, PLA is brittle while PP shows a ductile stress-strain behavior. The impact strength of PLA was drastically improved by adding lyocell while the impact strength of PP decreased. CM and IM composites do not show significant differences in fiber orientation. Despite a better compaction of IM composites, higher tensile strength values were achieved for CM samples due to a higher fiber length.
\end{abstract}

\section{Introduction}

Petrochemical-based polyolefins like polypropylene (PP) are common matrices for natural fiber-reinforced composites [14]. An overview about natural fibers and their composites may be taken from [5-9]. Nowadays the main application area of cellulose fiber-reinforced thermoplastics can be found in the automotive industry for nonvisible parts like indoor panels, dashboards, wheel covers, and so on $[10,11]$. In the last years the use of biobased matrices like polylactide (PLA) becomes more and more important $[12,13]$. In the near future it is envisaged to establish natural fiber-reinforced biobased plastics apart from the automotive industry for higher loaded components.

The present study gives an overview about the characteristics of cellulose fiber-reinforced PP and PLA composites and a possibility of improving the brittle character of PLA with regenerated cellulose fibers. Two different production procedures-compression molding $(\mathrm{CM})$ and injection molding (IM)-were used for composite production.

It is known that structure and properties of fibers and matrix are directly related to the composite characteristics. To elucidate the different mechanical properties of CM and IM cellulose fiber-reinforced PLA and PP composites, analyses of fiber orientation, compaction, and voids, fiber length distribution and fiber/matrix adhesion were carried out to clear up the following hypotheses:

(1) PLA has a higher hydrophilicity and polarity [14] than $\mathrm{PP}$, which displays a more nonpolar and hydrophobic character [15]. Due to this fact the fiber/matrix interaction between lyocell and PLA is assumed to be better than between lyocell and PP.

(2) Because of the higher stiffness and strength of PLA as well as the assumed better fiber/matrix adhesion with cellulose compared to PP, tensile strength and Young's modulus of lyocell/PLA should result in higher values in comparison to lyocell/PP.

(3) CM should lead to higher composite tensile characteristics due to higher fiber length and more aligned (oriented) fibers in production direction.

(4) The brittleness of PLA leads to a lower composite impact strength compared to the more ductile PP. 


\section{Materials and Methods}

Bright raw white Tencel ${ }^{\circledR}$ lyocell fibers with a fineness of 6.7 dtex (equivalent diameter $23.8 \mu \mathrm{m}$ ), a staple length of $60 \mathrm{~mm}$, a density of $1.5 \mathrm{~g} / \mathrm{cm}^{3}$, and a tensile strength of 301 $\pm 53 \mathrm{MPa}$ (median $+/$ - mean arithmetic deviation) at a gauge length of $20 \mathrm{~mm}$ and a testing speed of $10 \mathrm{~mm} / \mathrm{min}$ [16] were used for composite production. Fibers were supplied by Lenzing AG (Lenzing, Austria). PLA was used in fiber form (Ingeo fibers type SLN2660D) with a fineness of 6.7 dtex and a staple length of $64 \mathrm{~mm}$ produced by Eastern Textile Ltd. (Taipei, Taiwan) from a NatureWorks ${ }^{\mathrm{TM}}$ PLA 6202D (density: $1.24 \mathrm{~g} / \mathrm{cm}^{3}$, melting temperature: $160-170^{\circ} \mathrm{C}$, and glass transition temperature: $60-65^{\circ} \mathrm{C}$ ). Polypropylene Moplen EP 600V (PP) granules were supplied by LyondellBasell Polymers (LyondellBasell Industries Holdings, B.V., Rotterdam, NL) with a density of $0.9 \mathrm{~g} / \mathrm{cm}^{3}$, a Vicat softening temperature of $152^{\circ} \mathrm{C}$ and a melt flow rate $\left(\mathrm{MFR}_{230 ; 2,16}\right)$ of $100 \mathrm{~g} / 10 \mathrm{~min}$.

Composites were produced from PLA and PP matrices with 30 mass-\% lyocell as reinforcing fibers via compression (CM) and injection molding (IM). Previous studies have shown that a fiber mass fraction of $30 \%$ is best suited for reproducible production and comparison of IM and CM composites. With a fiber mass fraction of $20 \%$, a nonuniform distribution of the reinforcing fibers may occur in CM samples, whereas injection molded composites with a fiber mass fraction of $40 \%$ often show a high proportion of voids (compare [16]).

Semifinished products were produced by mixing lyocell and PLA fibers during a carding process. The multilayer webs contain fibers with a preferred orientation in machine direction but not $100 \%$ unidirectional direction [16]. PPbased composites were produced from multilayer webs containing the reinforcing fibers with a preferred orientation and polymer foils, produced from PP granules, via a film stacking process $[17,18]$. Prior to composite production the multilayer webs were predried at $103^{\circ} \mathrm{C}$ for $2 \mathrm{~h}$. Composite boards were produced with a hot pressing process from these semifinished products. Plates for granule production for the IM process were manufactured in a similar manner with a reduced press-time ( $3 \mathrm{~min}$ instead of $5 \mathrm{~min}$ ). These plates were shredded into granules for the following IM process [19]. More details about composite production are published in previous studies $[16,17]$. Reference samples were produced from neat PLA and PP matrices via CM and IM. Prior to mechanical characterization of polymers and composites, test specimens were conditioned according to DIN EN ISO 291 [20] at $23^{\circ} \mathrm{C}$ and $50 \%$ relative humidity for at least $18 \mathrm{~h}$.

Tensile tests (specimen type $1 \mathrm{~A}$ according to DIN EN ISO 527-2 [21]; gauge length: $100 \mathrm{~mm}$; testing speed $2 \mathrm{~mm} / \mathrm{min}$; elongation measurement via VideoXtens, Zwick/Roell $\mathrm{GmbH}$, Ulm, Germany) and unnotched Charpy impact tests (Charpy impact testing device type 5102, Zwick GmbH, Ulm, Germany) [22] of at least 5 specimens of matrices and composites as well as their fracture surfaces via SEM were investigated as described earlier in [16]. The apparent interlaminar shear strength (ILSS) of $10 \mathrm{CM}$ lyocell/PP and lyocell/PLA composites was characterized with doublenotched tensile tests as described in [23] (sample size: $60 \times 15$ $\times 2 \mathrm{~mm}^{3}$; notch distance: $10 \mathrm{~mm}$; testing speed: $0.5 \mathrm{~mm} / \mathrm{min}$; gauge length: $40 \mathrm{~mm}$ ). Shore $\mathrm{D}$ hardness measurements on the composites were done with a Shore D durometer type Z7206.07/00 (Zwick GmbH \& Co. KG, Ulm, Germany) at ten different positions.

Processed PLA and PP granules were investigated for their rheological properties with a Göttfert Rheograph 75 device (Göttfert Material Testing Machines $\mathrm{GmbH}$, Buchen, Germany) at $180^{\circ} \mathrm{C}$ with a capillary diameter of $15 \mathrm{~mm}$, a capillary length of $150 \mathrm{~mm}$, and a nozzle diameter of $1 \mathrm{~mm}$. The measurement was performed at eight different apparent shear rates $(72,180,450,1125,2811,7030$, and $175791 / s)$. The apparent viscosity with inlet pressure losses was determined.

To investigate the fiber length distribution, fibers were extracted from the composites using xylene and were analysed via image analysis (FibreShape software, IST AG, Vilters, Switzerland) as described in [24]. The investigation of fiber orientation and voids in the composite structure was carried out via synchrotron-radiation based $\mu$-computer tomography (SR $\mu$-CT) at DESY (Hamburg, Germany; see [25] for details). The SR $\mu$-CT micrographs were evaluated as reported in detail in [25].

Test results were statistically analysed with the open source R software (http://www.r-project.org/). A ShapiroWilk test was used for the analysis to a normal distribution. To proof if there are significant differences between the results of variable samples, for normally distributed results with homogenous variances, the Tukey test, and for data which do not follow a normal distribution the Wilcoxon test was chosen. All tests were performed with a level of significance $\alpha=0.05$. Significant differences are marked with different letters in the diagrams; an asterisk shows results which are not distributed normally.

\section{Results and Discussion}

3.1. Shore D Hardness. Shore D hardness values are shown for IM and CM neat matrices and their composites in Figure 1. The use of lyocell fibers does not significantly affect the hardness of PLA while the hardness of PP increased significantly by $6 \%$ because of the higher hardness of lyocell compared to PP. These findings are in agreement with results reported by Bourmaud and Baley [26]. The authors investigated the hardness of flax fibers and a PLA matrix via nanoindentation. Virgin flax fibers have shown a 1.8 times higher hardness than neat PLA. However, the hardness of the fibers decreases significantly after compression and injection molding to a similar value as reported for pure PLA. Considering PP and lyocell fibers, Lee et al. [27] have shown 5.6 times higher hardness for lyocell compared to PP analysed with nanoindentation carried out with an atomic force microscope (AFM).

3.2. Tensile Characteristics. Results have shown for both PP and PLA matrices higher values for IM matrices compared to CM matrices (see Table 1) which may be explained with the higher alignment of polymer chains in axial direction to the specimen due to higher pressure during IM [16]. The CM 

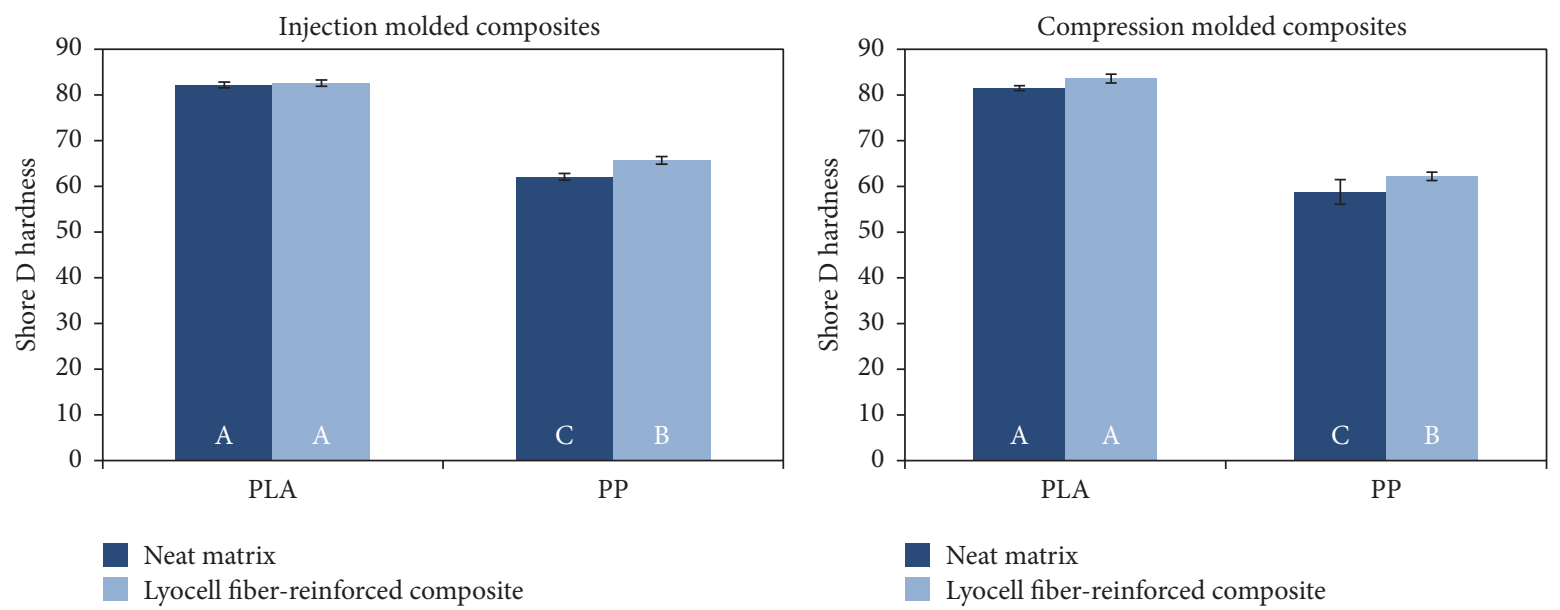

FIGURE 1: Shore D hardness of neat IM and CM matrices and lyocell fiber-reinforced composites (mean value \pm standard deviation; different letters show significant differences).

TABLE 1: Tensile characteristics of PLA, PP, and their composites (mean value \pm standard deviation).

\begin{tabular}{lccc}
\hline Material & Tensile strength in MPa & Young's modulus in GPa & Elongation at break in \% \\
\hline PP & $13.5( \pm 1.0)$ & $0.73( \pm 0.08)$ & $>200$ \\
PLA & $51.9( \pm 3.6)$ & $3.44( \pm 0.23)$ & $1.7( \pm 0.2)$ \\
Lyocell/PP & $33.3( \pm 3.5)$ & $2.50( \pm 0.29)$ & $3.8( \pm 0.8)$ \\
Lyocell/PLA & $87.6( \pm 8.1)$ & $9.95( \pm 0.75)$ & $3.6( \pm 0.4)$ \\
\hline & & Injection molded samples & $>200$ \\
PP & $19.6( \pm 0.3)$ & $1.40( \pm 0.22)$ & $2.0( \pm 0.2)$ \\
PLA & $59.9( \pm 0.2)$ & $3.57( \pm 0.25)$ & $2.7( \pm 0.4)$ \\
Lyocell/PP & $31.4( \pm 1.0)$ & $3.51( \pm 0.15)$ & $1.0( \pm 0.2)$ \\
Lyocell/PLA & $69.4( \pm 1.6)$ & $7.92( \pm 0.69)$ & \\
\hline
\end{tabular}

process causes no specific flow direction and therefore no preferred orientation of the polymer chains. Differences by different degrees of crystallisation were excluded with microscopic investigations of thin sections in polarised light. In the whole consideration, IM composites display significantly lower strength values than CM composites.

In general, the use of lyocell leads to significant reinforcement effects of both CM and IM produced PLA and PP composites. Because of the lower tensile strength of neat PP compared to PLA the reinforcing effect by lyocell was higher in PP. Considering CM samples, the tensile strength of PLA increased by $70 \%$, for PP even by $150 \%$. For the Young modulus reinforcing effects of $196 \%$ for PLA and $240 \%$ for PP were observed (compare Table 1).

These reinforcing effects were lower for IM samples. Considering the tensile strength, the values increased by $20 \%$ for PLA and $60 \%$ for PP, respectively. For the Young modulus reinforcing effects of $120 \%$ and $150 \%$ were determined for PLA and PP composites compared to the pure polymers. The results have shown significantly higher values for PLA composites and confirm the hypothesis that lyocell leads to higher strength and stiffness values in PLA compared to PP.

As visible in Table 1 the elongation at break of neat $\mathrm{PP}$ is significantly higher than that of PLA while the PP-based composites show only a slightly higher elongation than PLAbased composites. The higher elongation of PP compared to PLA should influence the impact performance which is analysed and discussed in Section 3.5.

To find out the reasons which may affect the different behavior of IM and CM samples (e.g., the lower tensile strength of IM composites compared to CM composites although the strength of the neat IM matrices is higher) like fiber orientation, voids, viscosity of the polymer melt, fiber/matrix adhesion, and fiber length distribution, further experiments were carried out. The results of these investigations are described in Sections 3.3 and 3.4.

3.3. Fiber Orientation, Voids, and Viscosity. Since CM samples were produced from multilayer webs, it is assumed that the fiber orientation shows no significant differences whether PLA or PP is used as a matrix. In contrast to IM the flow processes of the matrix during our used CM technique are negligible. Interestingly, a previous study has showed no significant differences between the mean orientation angles of IM and CM 30\% lyocell $6.7 \mathrm{dtex} /$ PLA composites [16]. The hypothesis which stated a higher fiber orientation of CM composites reinforced with 30 mass-\% lyocell must be discarded. In this study additional fiber orientation 


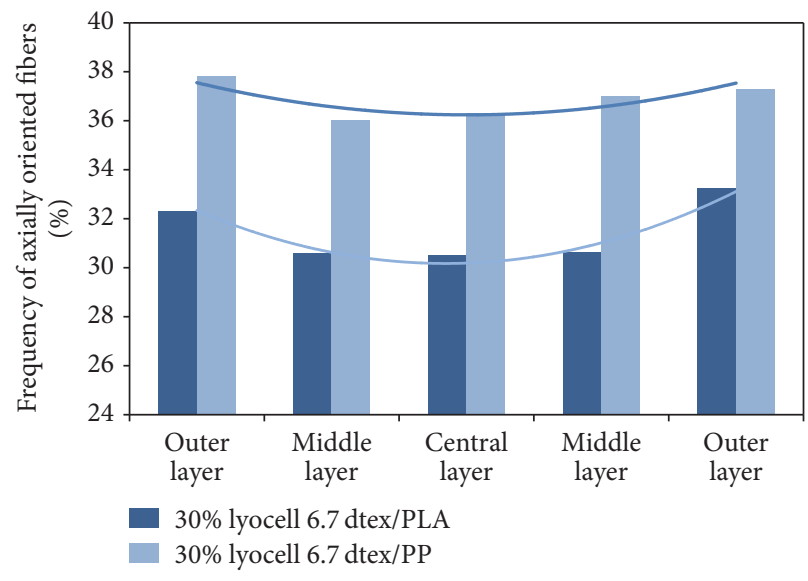

(a)

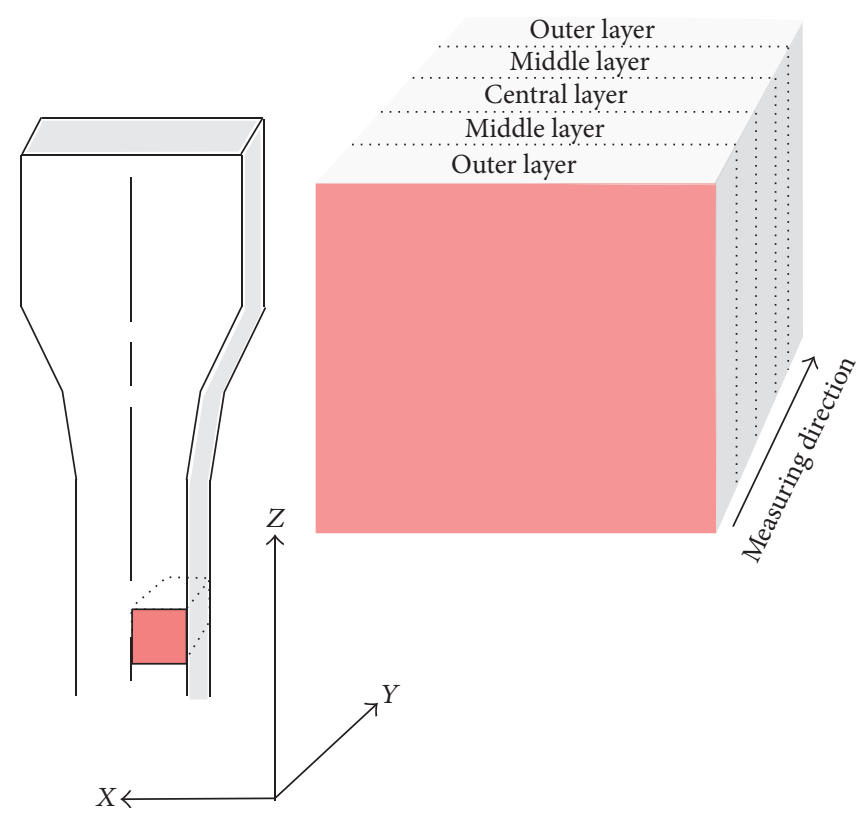

(b)

FIGURE 2: (a) Frequency of axially oriented fibers $\left(0-10^{\circ}\right)$ measured across a tensile test specimen of an IM PLA and IM PP composite (note interrupted $y$-axis). (b) Schematic of the measuring direction across sample height in the parallel section of a test specimen.

measurements were carried out with micrographs obtained from synchrotron-radiation based $\mu$-computer-tomography for IM samples with either a PLA or a PP matrix [25]. Figure 2(a) shows the frequency of axially oriented fibers $\left(0-10^{\circ}\right.$ fiber orientation angles) measured across the sample height in the parallel section of an IM lyocell/PLA and PP tensile test specimen (Figure 2(b)). The frequency of axially oriented fibers appears to be clearly higher in PP composites. Additionally, a higher number of axially oriented fibers were observed in the outer (shell) layers compared to the central (core) layer. The core layer usually shows a lower preferred fiber orientation and more fibers are oriented in perpendicular direction as reported in previous studies for IM samples [16, 28]. This trend is more evident for the PP composites (see Figure 2(a)) and may be explained with the viscosity of the matrices. The apparent viscosity was plotted logarithmically as a function of the apparent shear rate in Figure 3. PLA and PP display similar apparent viscosities at low shear rates but the higher the shear rate the higher the differences between PLA and PP. While the apparent shear rate decreases as a linear double logarithmic function for PP, for PLA a nonlinear decrease was observed with increasing shear rate. The viscosity of PP is clearly lower at higher shear rates resulting in a better flowability and alignment of fibers in flow direction during IM. The higher frequency of axially oriented fibers in PP should lead to a higher reinforcing effect as compared to PLA composites.

Since voids affect the mechanical characteristics of composites negatively, composites were additionally analysed for their void distribution on the basis of data obtained with the synchrotron-radiation based $\mu$-CT [25]. No voids were found in the IM composites and only a few voids were detected in

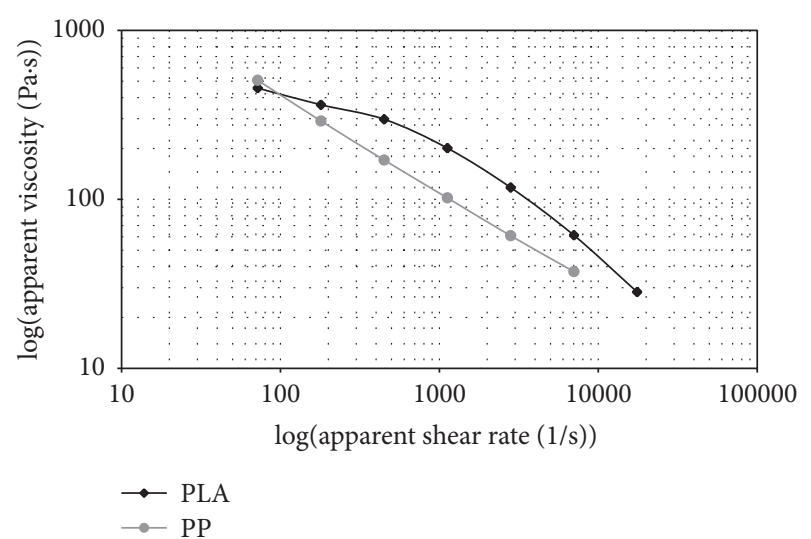

FIGURE 3: log-log plot of the apparent viscosity as a function of the apparent shear rate of neat PLA and PP.

the edge regions of the CM composites (2.1\% void volume). Therefore, the influence of voids is neglected in this study.

3.4. Fiber/Matrix Adhesion and Fiber Length Distribution. In order to obtain a characteristic value for the fiber/matrix adhesion, double-notched tensile tests were performed for $\mathrm{CM}$ composites. Figure 4 shows a significant variation of the apparent interlaminar shear strength (ILSS) between lyocell/PP and lyocell/PLA. Despite the lower viscosity of $\mathrm{PP}$ and an assumed better wetting of the fibers with the matrix the higher value was measured for lyocell/PLA with $22.2 \pm 1.9 \mathrm{MPa}$. Lyocell/PP resulted in a value of $11.6 \pm 1.0$. Hence, a lower critical fiber length $\left(L_{c}\right)$ is required for lyocell 


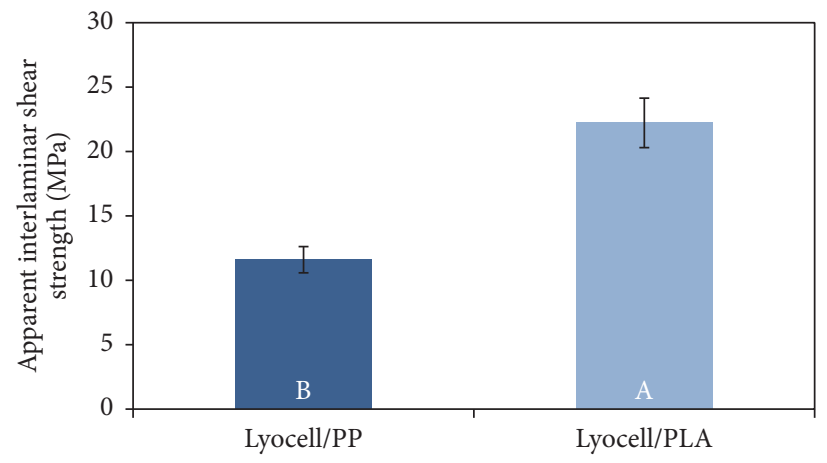

Figure 4: Apparent interlaminar shear strength (ILSS) of CM lyocell/PP and IM lyocell/PLA composites measured with double-notched tensile tests (mean value standard deviation, different letters show significant differences).

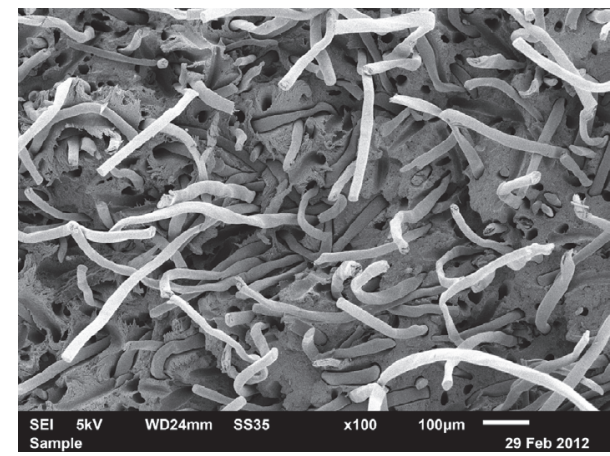

(a)

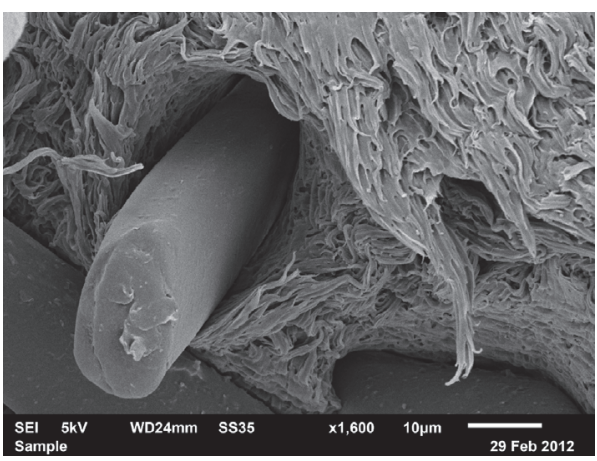

(c)

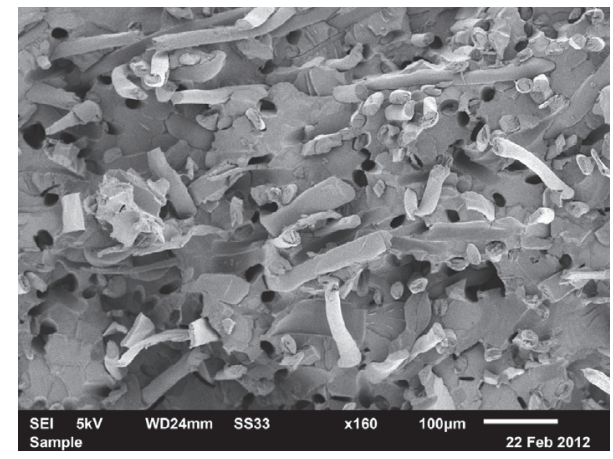

(b)

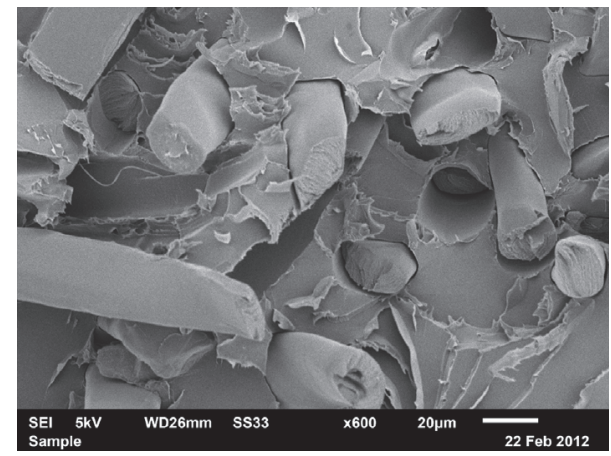

(d)

Figure 5: SEM micrographs of tensile fracture surfaces of IM lyocell/PP (a and c) and IM lyocell/PLA (b and d).

in PLA compared to lyocell in PP [29]. SEM investigations of tensile fracture surfaces shown in Figure 5 reveal clearly longer fiber pull-outs and larger gaps between lyocell fibers and PP indicating a worse bonding between fiber and matrix. Lower fiber pull-out lengths and smaller gaps are visible for lyocell in the PLA matrix revealing a better compatibility for lyocell/PLA.

The fiber length distribution was investigated for fibers extracted from the composites. Due to the high fiber length of CM composites it was not possible to measure the fiber length distribution with the image analysis procedure used in our study. The fibers were interlooped and not separable in as much quantity as necessary for a fiber length analysis.
Figure 6 shows three-dimensional views of a CM and an IM composite obtained with the $\mu$-CT analysis described in [25]. The fibers appear to be much longer in the CM composites. These $\mu$-CT investigations as well as results obtained in a previous study [16] lead to the assumption that the fiber length is not affected by the used compression molding technique. The initial fiber length used for CM composites was $60 \mathrm{~mm}$. In a previous study it was hypothesised that the fiber length $(L)$ of CM samples is multiple higher than a fiber length of $3.0 \mathrm{~mm}$ which is necessary to reach the maximum reinforcement effect in a PLA composite [16]. In contrast to this the fiber length is drastically reduced in IM composites due to granule production and shear loading 


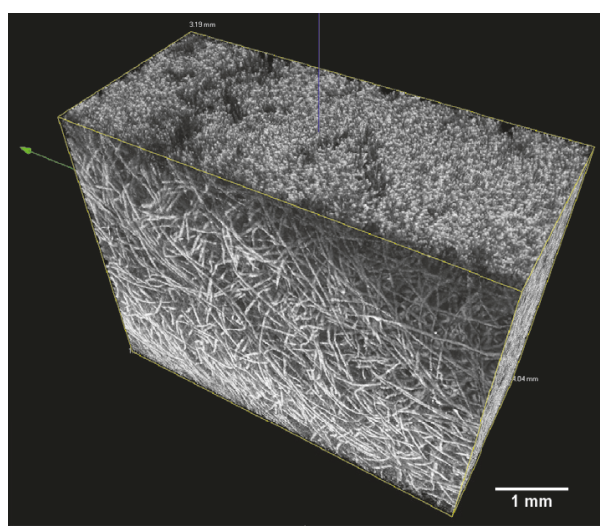

(a)

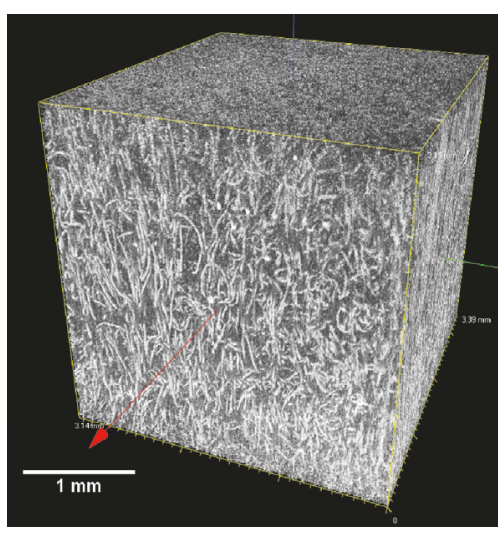

(b)

FIGURE 6: Synchrotron-radiation based $\mu$-CT micrographs of a compression molded (a) and an injection molded lyocell/PLA composite (b).

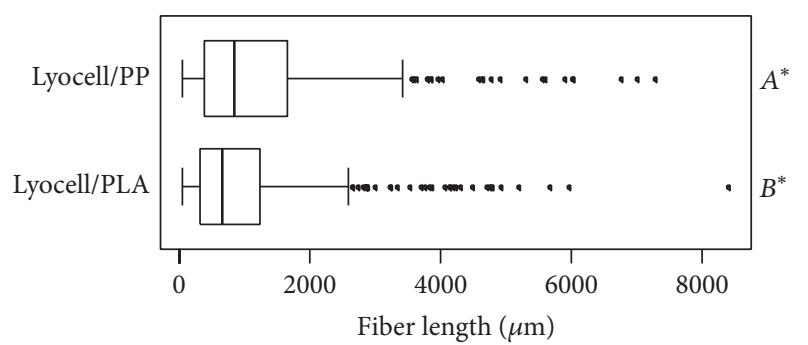

FIgURE 7: Box-Whisker plots of fiber length distribution of fibers extracted from IM lyocell/PP and IM lyocell/PLA composites (results do not follow a normal distribution; different letters show significant differences).

during the IM process. Granules were shredded to the same size from compression molded composite plates, assuming a similar initial fiber length in lyocell/PLA and lyocell/PP granules prior IM. The fiber length distribution in PP and PLA composites is shown in Figure 7 as Box-Whisker plots. According to the statistics, the median fiber length of lyocell extracted from PP is significantly higher than the median fiber length in the PLA composites. Lyocell fibers extracted from PP show a higher median value of $815 \mu \mathrm{m}$ and an average fiber length of $1130 \mu \mathrm{m}$ as compared to PLA (median fiber length: $661 \mu \mathrm{m}$, average fiber length: $983 \mu \mathrm{m}$ ). It is hypothesised that the fiber length is less reduced in a matrix of lower viscosity than in a matrix of higher viscosity.

The critical aspect ratio was evaluated from the critical fiber length $L_{c}$ for lyocell/PP and lyocell/PLA with single fiber pull-out tests in a previous study [29]. The critical aspect ratio $L_{c} / d$ ( $d=$ fiber diameter) was determined to be 21 for lyocell/PLA and 37 for lyocell/PP (the critical fiber aspect ratio describes the minimum aspect ratio which is required to achieve a reinforcement effect in a matrix). Due to the higher $L_{c}$ a higher aspect ratio is necessary to achieve a reinforcement effect in a PP matrix. The mean aspect ratio(L/d) of the extracted fibers was calculated to be 28 for lyocell/PLA and 32 for lyocell/PP resulting in a 1.3 times higher aspect ratio for lyocell/PLA compared to the critical aspect ratio. The aspect ratio of lyocell in PP is by a factor of 0.9 lower. Thereby, lyocell/PLA contains $46 \%$ fibers with an aspect ratio higher than the critical aspect ratio while lyocell/PP only contains $33 \%$ fibers having an aspect ratio higher than the critical aspect ratio.

3.5. Calculation. The theoretical tensile strength was approximately calculated according to Kelly and Tyson [30] (see (1)) with the tensile strength of the composite $\sigma_{C}$, the fiber volume fraction $V_{F}$, the fiber tensile strength $\sigma_{F}$, the matrix volume fraction $V_{M}$, and the tensile strength of the matrix $\sigma_{M}$.

$$
\sigma_{C}=\eta_{L} \cdot \eta_{O} \cdot V_{F} \cdot \sigma_{F}+V_{M} \cdot \sigma_{M} .
$$

$\eta_{L}$ is the fiber length efficiency factor (see (2) for $L \geq L_{c}$ and (3) for $L<L_{c}$ ). The fiber orientation efficiency factor $\eta_{O}$ is calculated according to Krenchel [31] in (4) with $a$, the amount of fibers having an orientation angle $\phi$. Aspects like voids and fiber/matrix adhesion are not considered in this model. Data used for this calculation are summarised in Table 2.

$$
\begin{aligned}
& \eta_{L}=1-\frac{L_{c}}{2 \cdot L} \quad \text { for } L \geq L_{c} \\
& \eta_{L}=\frac{L}{2 \cdot L_{c}} \quad \text { for } L<L_{c} \\
& \eta_{O}=\sum a \cdot\left(\cos ^{4}(\phi)\right)
\end{aligned}
$$

As shown in Figure 8, the calculated tensile strength is higher than the measured values, especially for PPbased composites. The deviation between theoretical tensile strength and experimentally determined tensile strength was up to $-10 \%$ for PLA composites while the deviation for PP composites was up to $-61 \%$ despite the higher fiber orientation. It is assumed that this effect is mainly based on the lower fiber/matrix interaction between cellulose and PP compared to PLA as proven in Figures 4 and 5. Despite the previous discussed higher reinforcing effect for lyocell fibers 


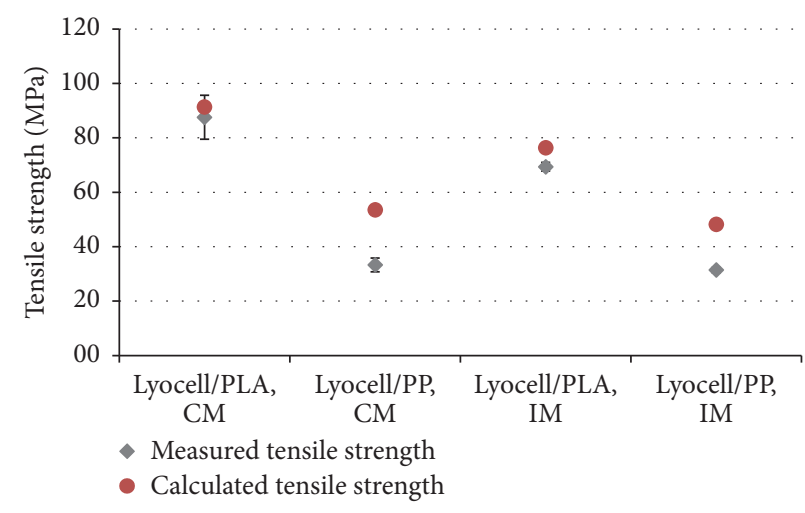

(a)

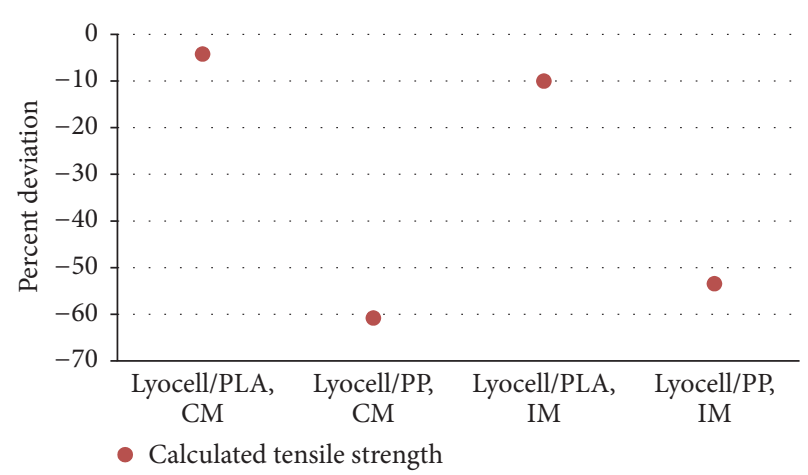

(b)

FIGURE 8: Measured tensile strength (mean value standard deviation) of CM and IM lyocell/PLA and lyocell/PP composites compared to calculated strength values according to Kelly and Tyson (a) and percent deviation between measured values and calculated values (b).

TABLE 2: Data used for tensile strength calculation with the KellyTyson model according to (1).

\begin{tabular}{lcccc}
\hline \multirow{2}{*}{ Characteristic } & \multicolumn{2}{c}{ PLA } & \multicolumn{2}{c}{ PP } \\
& CM & IM & CM & IM \\
\hline$\sigma_{F}$ in $\mathrm{MPa}$ & 301 & 301 & 301 & 301 \\
$\sigma_{M}$ in $\mathrm{MPa}$ & 52 & 60 & 14 & 20 \\
$V_{F}$ in $\%$ & 26 & 26 & 21 & 21 \\
$V_{M}$ in $\%$ & 74 & 74 & 79 & 79 \\
$\eta_{L}$ & 1.000 & 0.621 & 1.000 & 0.757 \\
$\eta_{O}$ & 0.672 & 0.655 & 0.672 & 0.677 \\
\hline
\end{tabular}

in a PP matrix, the reinforcing potential of lyocell in a PLA matrix seems to be higher with respect to the tensile strength. The high deviations between measured and calculated tensile strength values make it necessary to develop a new model, especially for cellulose fiber-reinforced composites in future research activities (see [32]).

3.6. Unnotched Charpy Impact Strength. Figure 9 shows the unnotched Charpy impact strength of the different matrices and their composites manufactured with the CM and IM process. Due to the different thickness of CM and IM samples ( $2 \mathrm{~mm}$ for CM samples and $4 \mathrm{~mm}$ for IM samples), the results are not directly comparable. The impact strength is considerably affected by the sample thickness [33, 34]. Considering CM samples unlike the brittle PLA matrix no break occurred for neat PP due to the small sample thickness and the high flexibility of PP. The CM composites showed the highest impact strength for lyocell/PLA with $51.9 \pm 6.5 \mathrm{~kJ} / \mathrm{m}^{2}$. This is an improvement by $300 \%$. For lyocell/PP a value of $43.7 \pm$ $4.1 \mathrm{~kJ} / \mathrm{m}^{2}$ was determined indicating an increasing brittleness compared to neat PP. The established hypothesis assuming increasing impact strength by the use of a more ductile matrix must be rejected for CM composites. This phenomenon may be justified with the fiber/matrix adhesion and the fiber length. In general, very good fiber/matrix adhesion leads to composites with good strength and stiffness, while weak

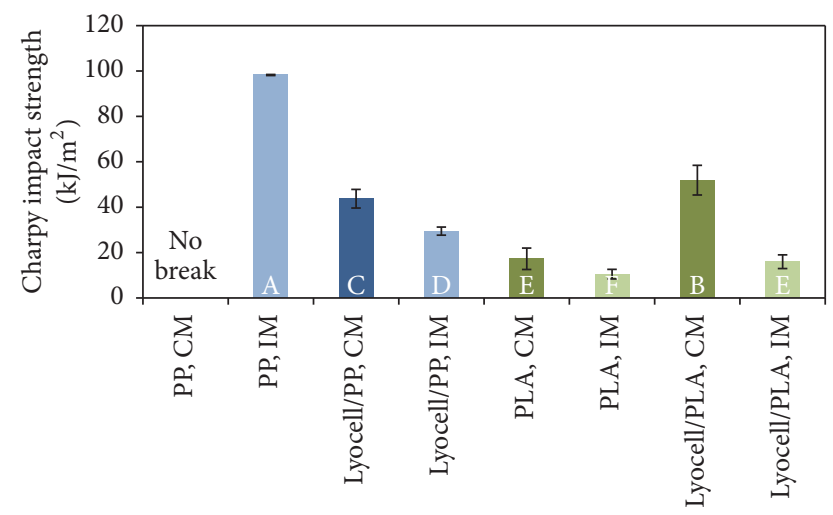

FIGURE 9: Unnotched Charpy impact strength of PP and PLA as well as their lyocell fiber-reinforced composites produced with $\mathrm{CM}$ and IM (mean value with standard deviation, different letters show significant differences; please note that either IM samples or CM samples should be compared with each other due to a different sample thickness of $4 \mathrm{~mm}$ for IM samples and $2 \mathrm{~mm}$ for CM samples).

fiber/matrix interaction may result in composites with a low strength. But the occurring fiber pull-outs lead to good energy absorption during fracture and composites with a good impact performance are the consequence $[35,36]$. Due to the less hydrophobic character of PLA, the adhesion of lyocell fibers in a PLA matrix is considerably better than that in a PP matrix. Since the CM samples contain ductile fibers with $L \gg L_{c}$, more energy is dissipated during a fiber pull-out with a stronger bonding between fiber and matrix as observed for lyocell fibers in the PLA matrix (compare Figure 4).

With the IM samples, different trends were observed. While for PLA a reinforcing effect by $150 \%$ was determined, the impact strength of lyocell/PP was drastically reduced compared to pure PP. Nevertheless, it is significantly higher than the impact strength of lyocell/PLA. The different behavior can be explained with the stress-strain characteristics of lyocell, PLA and PP (compare Figure 10). While PLA has a low elongation and displays a brittle behavior, PP shows a 


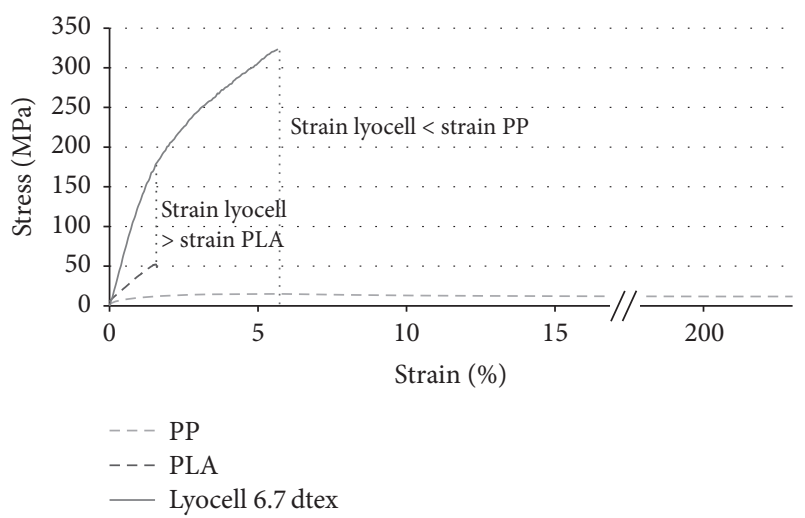

FIgURE 10: Typical stress-strain curves of neat PLA, neat PP, and lyocell fibers.

lower strength and stiffness but significantly higher ductility (Figure 10). Lyocell displays a significantly higher elongation than PLA and thus leads to an increase in impact strength for both IM and CM lyocell/PLA composites. However, compared to PP the elongation at break of lyocell is lower resulting in a reduction of the ductility of lyocell/PP. The higher impact strength of the IM PP composite compared to the IM PLA composite can be explained with the short fiber length and the different ductility of the neat matrices. In contrast to $\mathrm{CM}$ composites short fibers were used as reinforcement. The energy absorption by fiber pull-out is limited. A certain fiber length is necessary to absorb energy by fiber pull-out during crack propagation after impact. In this case the more ductile character of PP compared to PLA has a more important role as compared to long fiber-reinforced composites.

In the whole consideration the hypothesis of increasing impact strength by using more ductile lyocell fibers cannot be refuted for lyocell/PLA composites. Using a more ductile matrix like PP leads to an improvement of the impact strength of short fiber-reinforced composites compared to the use of a brittle PLA matrix because of the limited fiber pull-out during crack propagation after impact due to the short fiber length. In this case the ductility of the matrix is more important. In contrast to this in long fiber-reinforced composites the energy absorbing fiber pull-outs as a result of better fiber/matrix adhesion in lyocell/PLA lead to a significant improvement of impact strength compared to lyocell/PP with a weak fiber/matrix adhesion.

\section{Summary and Conclusions}

The results presented here demonstrate a high potential of PLA as a matrix for cellulose fiber-reinforced composites. Results have shown for both CM and IM composites significantly higher tensile strength and Young's modulus values for PLA-based composites compared to PP-based composites. However, the elongation at break of PLA is significantly lower, resulting in a brittle behavior, which in turn has a negative effect on the impact properties. By using lyocell as reinforcement the brittle nature of PLA decreases significantly while the impact strength of PP was reduced. Different impact behavior was observed for short fiber-reinforced IM composites compared to long fiber-reinforced CM composites. The high ductility of PP leads to higher impact strength for IM short fiber-reinforced lyocell/PP than for lyocell/PLA composites while a higher value was measured for $\mathrm{CM}$ long fiber-reinforced lyocell/PLA than for lyocell/PP composites because of higher energy absorption during fracture. Since no significant differences were measured with respect to the fiber orientation in IM and CM composites and the IM composites containing a lower volume fraction of voids the different behavior of CM and IM samples is predominantly based on the fiber length. Fibers in IM composites are too short to reach the maximum possible mechanical characteristics. Despite a better blending of lyocell fibers with PP due to the lower viscosity at higher shear rates, higher interfacial shear strength was measured for PLA-based composites. SEM micrographs show long fiber pull-outs with big gaps between lyocell and PP which appear to be smaller for lyocell in PLA leading to a better load transfer from the matrix to the fiber. This effect is based on the hydrophilic character of lyocell and the less hydrophobic character of PLA compared to PP. In the whole consideration the improved ductility of lyocell/PLA in combination with good tensile characteristics expands the possibilities for impact loaded construction materials for higher claimed products. In future research studies it should be checked whether it is possible to insert longer lyocell fibers in IM composites. Due to better wetting it is hypothesised that tensile and impact characteristics of IM composites may be enhanced above the characteristics of CM composites by using longer reinforcing fibers.

\section{Disclosure}

Parts of the results of this study were presented on the ICCE-22 (International Conference on Composites/NanoEngineering, International Community for Composites/ Nano-Engineering), 2014, and ICNF (International Conference on Natural Fibers), 2015.

\section{Conflicts of Interest}

The authors declare that there are no conflicts of interest regarding the publication of this paper.

\section{Acknowledgments}

The authors thank Professor Dr.-Ing. Gerhard Ziegmann (University of Technology, PuK, Clausthal-Zellerfeld, Germany) and Dipl.-Ing. (FH) Herbert Enzler (University of Technology, PuK, Clausthal-Zellerfeld, Germany) for their support during injection molding, Dr. Stefan Kirchberg (University of Technology, PuK, Clausthal-Zellerfeld, Germany) for the viscosity measurements, and M.S. Katharina Albrecht (University of Applied Sciences, Bremen, Germany) for fiber extraction. They also acknowledge the Deutsches Elektronen Synchrotron (DESY) and the Helmholtz Gesellschaft Geesthacht (HZG) for funding the measurements on the fiber 
orientation, in particular Dr. Fabian Wilde (HZG) for his support during our beam time.

\section{References}

[1] A. K. Bledzki and J. Gassan, "Composites reinforced with cellulose based fibres," Progress in Polymer Science, vol. 24, no. 2, pp. 221-274, 1999.

[2] J. K. Pandey, S. H. Ahn, C. S. Lee, A. K. Mohanty, and M. Misra, "Recent advances in the application of natural fiber based composites," Macromolecular Materials and Engineering, vol. 295, no. 11, pp. 975-989, 2010.

[3] J. Summerscales, N. P. J. Dissanayake, A. S. Virk, and W. Hall, "A review of bast fibres and their composites. Part 1. Fibres as reinforcements," Composites Part A: Applied Science and Manufacturing, vol. 41, no. 10, pp. 1329-1335, 2010.

[4] J. Summerscales, N. Dissanayake, A. Virk, and W. Hall, "A review of bast fibres and their composites. Part 2-composites," Composites Part A: Applied Science and Manufacturing, vol. 41, no. 10, pp. 1336-1344, 2010.

[5] J. Müssig, H. Fischer, N. Graupner, and A. Drieling, “Testing methods for measuring physical and mechanical fibre properties (plant and animal fibres," in Industrial Applications of Natural Fibres - Structure, Properties and Technical Applications, J. Müssig, Ed., pp. 269-310, John Wiley \& Sons, Ltd, 2010.

[6] R. D. Anandjiwala and S. Blouw, "Composites from bast fibres Prospects and potential in the changing market environment," Journal of Natural Fibers, vol. 4, no. 2, pp. 91-901, 2007.

[7] C. Baley, "A review of biocomposite development," JEC Composites Magazine, vol. 46, no. 46, pp. 32-33, 2009.

[8] T. Gurunathan, S. Mohanty, and S. K. Nayak, "A review of the recent developments in biocomposites based on natural fibres and their application perspectives," Composites Part A: Applied Science and Manufacturing, vol. 77, pp. 1-25, 2015.

[9] K. L. Pickering, M. G. A. Efendy, and T. M. Le, "A review of recent developments in natural fibre composites and their mechanical performance," Composites Part A: Applied Science and Manufacturing, vol. 83, pp. 98-112, 2016.

[10] G. Koronis, A. Silva, and M. Fontul, "Green composites: a review of adequate materials for automotive applications," Composites Part B: Engineering, vol. 44, no. 1, pp. 120-127, 2013.

[11] M. Barth and M. Carus, Carbon footprint and sustainability of different natural fibre for biocomposites and insulation material. study providing data for the automotive and insulation industry, 2015, http://www.bio-based.eu/ecology, http://bio-based.eu/download/?did=14089\&amp;file=0.

[12] P. K. Bajpai, I. Singh, and J. Madaan, "Comparative studies of mechanical and morphological properties of polylactic acid and polypropylene based natural fiber composites," Journal of Reinforced Plastics and Composites, vol. 31, no. 24, pp. 1712-1724, 2012.

[13] D. Garlotta, "A literature review of poly(lactic acid)," Journal of Polymers and the Environment, vol. 9, no. 2, pp. 63-84, 2001.

[14] H. Endres and A. Siebert-Raths, Engineering Biopolymers: Markets, Manufacturing, Properties and Applications, Carl Hanser Verlag, Munich, DE, 1st edition, 2011.

[15] G. Venkata Reddy, S. Venkata Naidu, and T. Shobha Rani, "A study on hardness and flexural properties of kapok/sisal composites," Journal of Reinforced Plastics and Composites, vol. 28, no. 16, pp. 2035-2044, 2009.
[16] N. Graupner, G. Ziegmann, F. Wilde, F. Beckmann, and J. Müssig, "Procedural influences on compression and injection moulded cellulose fibre-reinforced polylactide (PLA) composites: Influence of fibre loading, fibre length, fibre orientation and voids," Composites Part A: Applied Science and Manufacturing, vol. 81, pp. 158-171, 2016.

[17] N. Graupner and J. Müssig, "A comparison of the mechanical characteristics of kenaf and lyocell fibre reinforced poly(lactic acid) (PLA) and poly(3-hydroxybutyrate) (PHB) composites," Composites Part A: Applied Science and Manufacturing, vol. 42, no. 12, pp. 2010-2019, 2011.

[18] N. Graupner and J. Müssig, “The influence of lyocell and kenaf fibres on the mechanical characteristics of poly(lactic acid) (PLA) composites," Journal of Biobased Materials and Bioenergy, vol. 6, no. 4, pp. 500-507, 2012.

[19] F. Beckmann, "Verfahren zum Herstellen von Thermoplast gebundenem Naturfasermaterial in schütt- und rieselfähiger Form (2001), EP1307333B1".

[20] "DIN EN ISO 291:2005 - Kunststoffe - Normalklimate für Konditionierung und Prüfung, Deutsche Norm. - in German (2006)".

[21] “DIN EN ISO 527-2 - Kunststoffe: Bestimmung der Zugeigenschaften; Teil 2 Prüfbedingungen für Form- und Extrusionsmassen, Deutsche Norm. - in German (1996)".

[22] "DIN EN ISO 179:1996 - Kunststoffe - Bestimmung der CharpySchlagzähigkeit, Deutsche Norm. - in German (1997)".

[23] N. Graupner, H. Fischer, G. Ziegmann, and J. Müssig, "Improvement and analysis of fibre/matrix adhesion of regenerated cellulose fibre reinforced PP-, MAPP- and PLA-composites by the use of Eucalyptus globulus lignin," Composites Part B: Engineering, vol. 66, pp. 117-125, 2014.

[24] N. Graupner, K. Albrecht, G. Ziegmann, H. Enzler, and J. Müssig, "Influence of reprocessing on fibre length distribution, tensile strength and impact strength of injection moulded cellulose fibre-reinforced polylactide (PLA) composites," Express Polymer Letters, vol. 10, no. 8, pp. 647-663, 2016.

[25] N. Graupner, F. Beckmann, F. Wilde, and J. Müssig, "Using synchroton radiation-based micro-computer tomography (SR $\mu$ $\mathrm{CT}$ ) for the measurement of fibre orientations in cellulose fibrereinforced polylactide (PLA) composites," Journal of Materials Science, vol. 49, no. 1, pp. 450-460, 2014.

[26] A. Bourmaud and C. Baley, "Effects of thermo mechanical processing on the mechanical properties of biocomposite flax fibers evaluated by nanoindentation," Polymer Degradation and Stability, vol. 95, no. 9, pp. 1488-1494, 2010.

[27] S.-H. Lee, S. Wang, G. M. Pharr, and H. Xu, "Evaluation of interphase properties in a cellulose fiber-reinforced polypropylene composite by nanoindentation and finite element analysis," Composites Part A: Applied Science and Manufacturing, vol. 38, no. 6, pp. 1517-1524, 2007.

[28] K. Albrecht, E. Baur, H. Endres, R. Gente et al., "Measuring fibre orientation in sisal fibre-reinforced, injection moulded polypropylene? Pros and cons of the experimental methods to validate injection moulding simulation," Composites Part A: Applied Science and Manufacturing, vol. 95, pp. 54-64, 2017.

[29] N. Graupner, J. Rößler, G. Ziegmann, and J. Müssig, "Fibre/matrix adhesion of cellulose fibres in PLA, PP and MAPP: A critical review of pull-out test, microbond test and single fibre fragmentation test results," Composites Part A: Applied Science and Manufacturing, vol. 63, pp. 133-148, 2014. 
[30] A. Kelly and W. R. Tyson, "Fiber strengthened materials," in High-strength materials, V. F. Zackay, Ed., John Wiley \& Sons, Berkeley, USA, 1964.

[31] H. Krenchel, Fibre reinforcement: Theoretical and practical investigations of the elasticity and strength of fibre-reinforced materials [Ph.D. thesis], Technical University of Denmark, Laboratory of Structural Research, Copenhagen, DK, 1964.

[32] N. Graupner, G. Ziegmann, and J. Müssig, "Composite models for compression moulded long regenerated cellulose fibrereinforced brittle polylactide (PLA)," Composites Science and Technology, 2017, In press.

[33] R. A. Malloy, "The design process and material selection," in Plastic part design for injection moulding - an introduction, R. A. Malloy, Ed., pp. 127-183, Carl Hanser Verlag, Munich, DE, 1994.

[34] L. J. Broutman and S. M. Krishnakumar, "Impact strength of polymers: 1 . The effect of thermal treatment and residual stress," Polymer Engineering \& Science, vol. 16, no. 2, pp. 74-81, 1976.

[35] J. L. Thomason and M. A. Vlug, "Influence of fibre length and concentration on the properties of glass fibre-reinforced polypropylene: 4. Impact properties," Composites Part A: Applied Science and Manufacturing, vol. 28, no. 3, pp. 277-288, 1997.

[36] N. Graupner, D. Labonte, H. Humburg, T. Buzkan et al., "Functional gradients in the pericarp of the green coconut inspire asymmetric fibre-composites with improved impact strength, and preserved flexural and tensile properties," Bioinspiration \& Biomimetics, vol. 12, no. 2, Article ID 026009, 2017. 

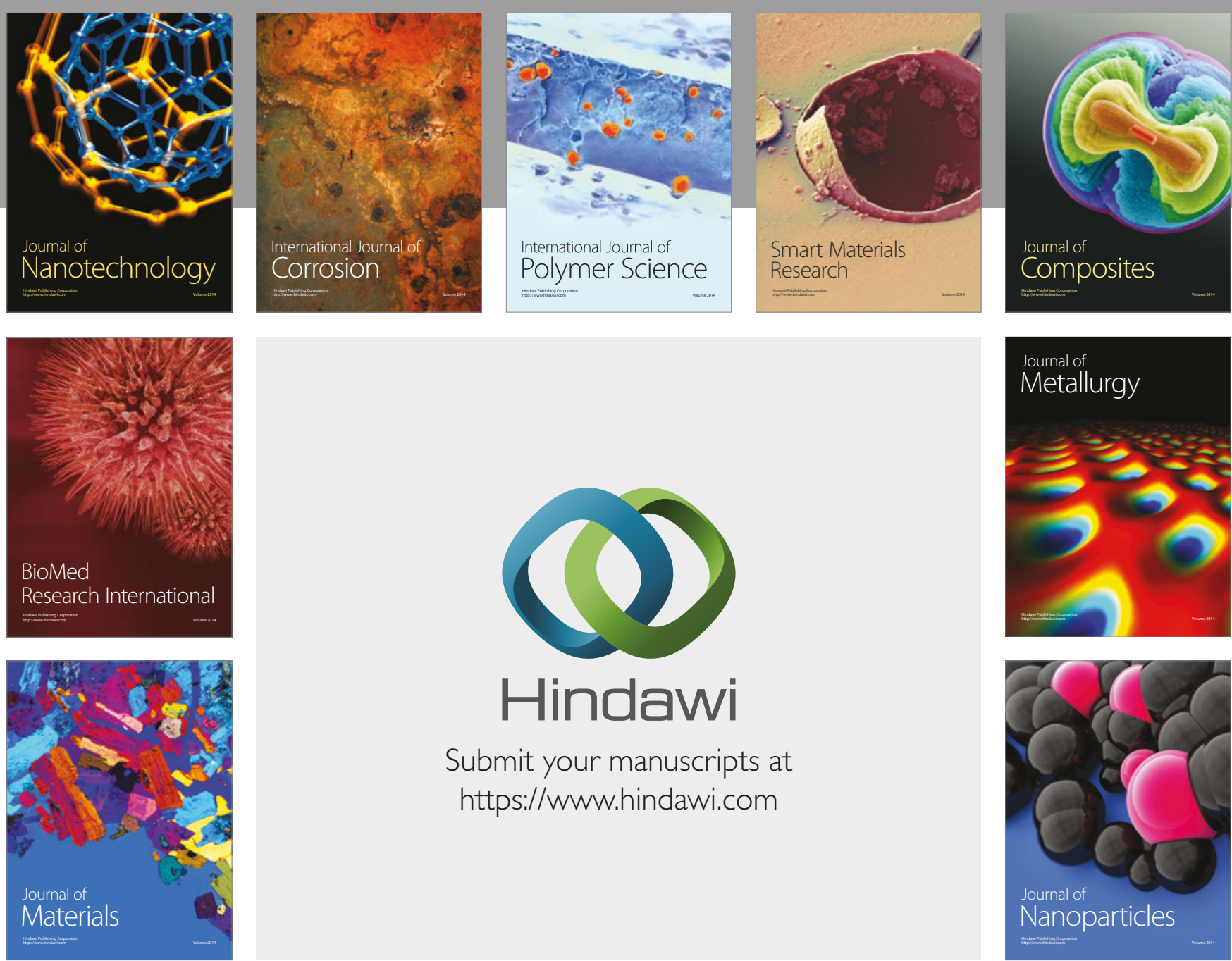

\section{Hindawi}

Submit your manuscripts at

https://www.hindawi.com
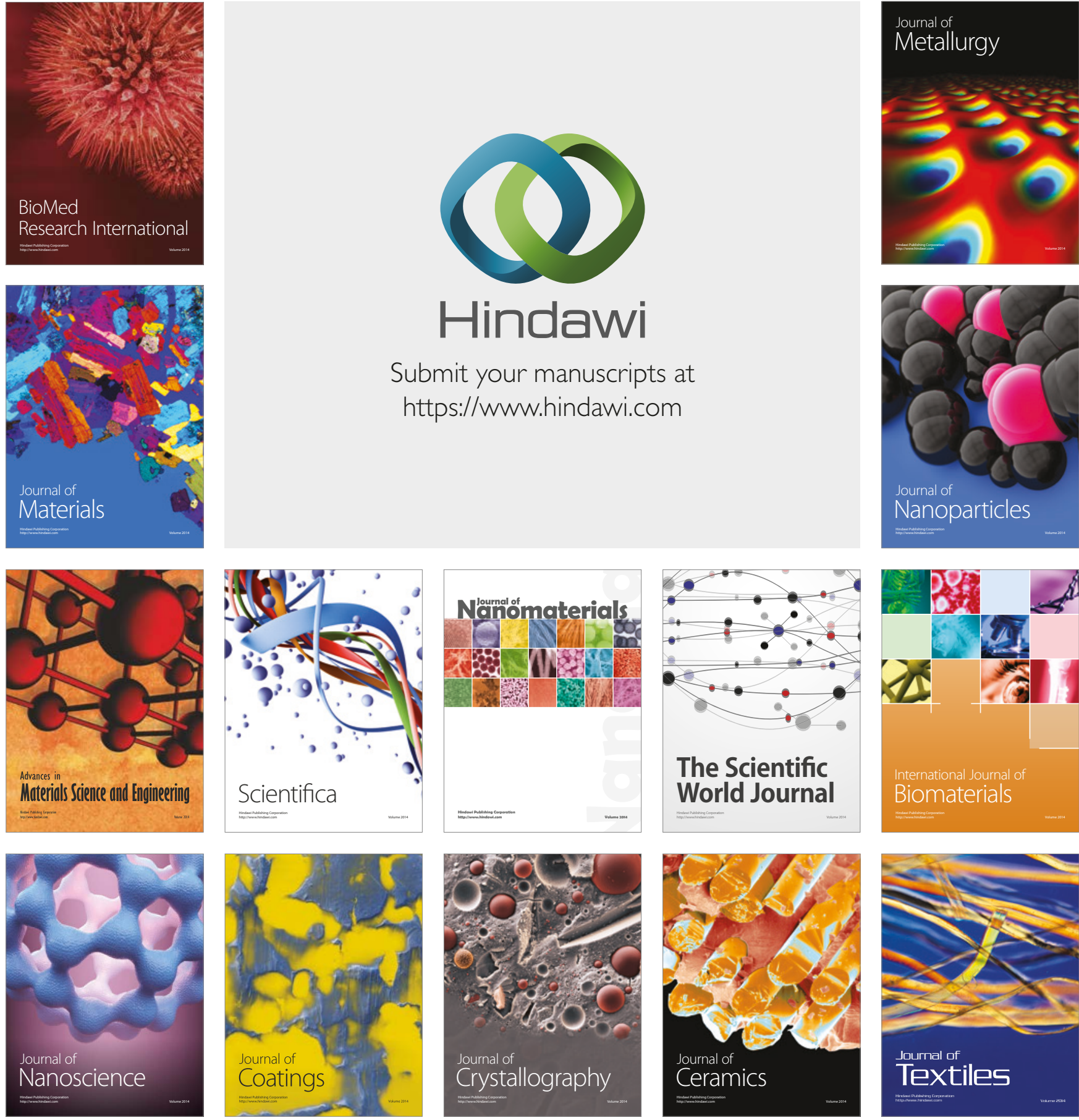

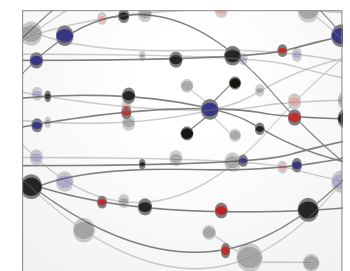

The Scientific World Journal
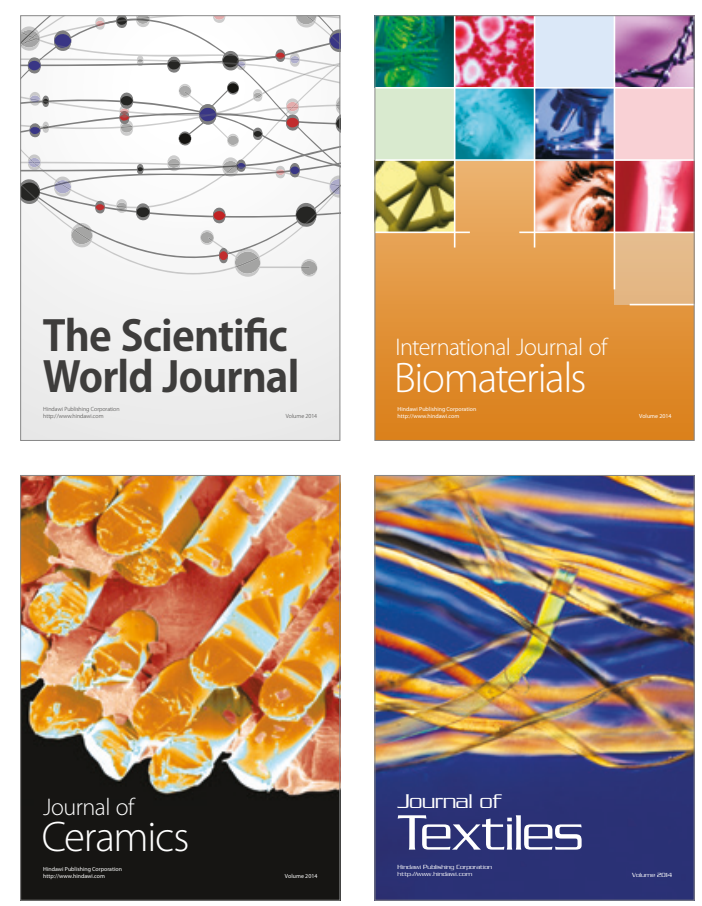